\title{
SERUM FLUORIDE LEVELS IN AMBULANCE STAFF AFTER COMMENCEMENT OF METHOXYFLURANE ADMINISTRATION COMPARED TO META-ANALYSIS RESULTS FOR THE GENERAL PUBLIC
}

\author{
SERAH JOAN ALLISON ${ }^{1,2}$, PAUL DAVID DOCHERTY ${ }^{1,3}$, DIRK PONS $^{1}$, and JAMES GEOFFREY CHASE ${ }^{1}$ \\ ${ }^{1}$ University of Canterbury, Christchurch, New Zealand \\ Department of Mechanical Engineering \\ ${ }^{2}$ Wellington Free Ambulance, Wellington, New Zealand \\ Healthcare Services \\ ${ }^{3}$ Furtwangen University, Furtwangen im Schwarzwald, Germany \\ Institute of Technical Medicine
}

\begin{abstract}
Objectives: Ambulance officers administering methoxyflurane as an inhalational analgesic may be exposed to trace vapor. Fluoride is a methoxyflurane metabolite, and has been associated with acute renal failure in anesthesia patients and skeletal fluorosis with chronic elevated serum levels from other sources. However, there has been no direct measurement of serum fluoride in occupationally exposed ambulance officers. Thus, this study directly measures serum fluoride over a prolonged period in order to determine renal toxic and skeletal fluorosis risk to ambulance officers who are administering methoxyflurane. Material and Methods: Serum inorganic fluoride concentrations were measured in a prospective observational study of 12 emergency medical technicians (EMTs). The study took 7 serum fluoride measurements over 24 months. A meta-analysis of healthy adult serum fluoride ranges was also conducted. Results: The typical healthy adult serum fluoride range was determined to be $0.21-2.11 \mu \mathrm{mol} / \mathrm{l}(\mathrm{p}<0.001)$. The EMTs' baseline median (IQR) serum fluoride concentrations were $0.4 \mu \mathrm{mol} / 1(0.2 ; 1.0)$ with maximum $1.6 \mu$ mol/l. The EMTs' overall median serum fluoride was $0.4 \mu \mathrm{mol} / 1$ [ $[0.2 ; 1.3]$ with maximum $4.0 \mu \mathrm{mol} / \mathrm{l}$, usually within healthy reference ranges. All results were $\leq 10 \%$ of the suggested single-dose renal toxic threshold. One result was above a threshold for skeletal fluorosis. The highest measured serum fluoride was $24 \%$ of the lowest level associated with radiologic evidence of fluorosis. There was no evidence overall of increasing serum fluoride levels. Conclusions: There was no evidence that EMTs' exposure to methoxyflurane resulted in sustained increased serum fluoride. These results imply EMTs' occupational safety from acute renal toxicity when activated carbon filtration is used on patient exhalation. However, 1 serum fluoride result above a skeletal fluorosis threshold suggests that the risk of mild skeletal fluorosis cannot be excluded. Int J Occup Med Environ Health. 2021;34(6):767-77
\end{abstract}

Key words:

meta-analysis, prospective studies, fluorides, ambulances, fluoride poisoning, methoxyflurane

\footnotetext{
Funding: this research was supported by Science for Technology and Innovation (grant No. 2019-S3-CRS entitled "NZ National Science Challenge 7," grant manager: James Geoffrey Chase) and by NZ Tertiary Education Commission (TEC) (grant No. 3705718 entitled "MedTech CoRE (Centre of Research Excellence)," grant manager: James Geoffrey Chase).

Received: August 18, 2020. Accepted: March 11, 2021.

Corresponding author: Serah Joan Allison, University of Canterbury, Department of Mechanical Engineering, Kirkwood Ave. 20, 8041 Christchurch, New Zealand (e-mail: serah.allison@protonmail.com).
} 


\section{INTRODUCTION}

Methoxyflurane is a volatile halogenated ether [1] recommended for use as an inhaled analgesic for pre-hospital and other pain relief [2,3]. Methoxyflurane undergoes hepatic metabolism [1], producing fluoride and other products. Approximately two-thirds of these products are excreted in urine over subsequent days [4]. An association exists between increased fluoride metabolite concentration in blood and increased nephrotoxicity [5-8]. A highdose anesthetic use of methoxyflurane has thus been associated with renal failure $[9,10]$.

In contrast, low-dose analgesia administered to patients and the environmental concentrations to which healthcare staff are exposed are believed to be well below a level that might cause renal toxicity [6]. Calculations of risk have relied on extrapolation over several orders of magnitude and, therefore, require verification [7,11]. International limit values (ILVs) have been set at $2 \mathrm{ppm}$ for 8-hour exposure [12]. In a clinical setting with modern use, cohort mean 8-hour exposure to methoxyflurane was below the ILVs. However, the highest 8-hour exposure in that setting was $2.88 \mathrm{ppm}$, which exceeds those limits [13]. Direct measurement of fluoride levels in workers consistently exposed to methoxyflurane has not been undertaken and is, therefore, needed to confirm renal safety.

Another reason for direct measurement is to ascertain temporal effects such as fluoride accumulation due to repeated exposure. Approximately one-third of absorbed methoxyflurane and metabolites remain in the body 9 days following exposure [4]. Rodent skeletal fluoride content was found to increase following methoxyflurane exposure $[14,15]$, suggesting that compartmental storage and saturation might result in a delayed increase in serum fluoride. This outcome suggests, for frequently exposed individuals, the possibility of serum fluoride reaching renal toxic levels with some delay. Therefore, direct measurement of serum fluoride over a prolonged period is required to confirm an absence of compartment saturation with delayed serum fluoride increase.

A further health concern, i.e., skeletal fluorosis, is caused by the accumulation of fluoride in bones over a prolonged period leading to stiffness, pain, connective tissue calcification, osteosclerosis, bone deformities, and increased fracture risk [16,17]. Skeletal fluorosis might be a potential long-term occupational hazard due to fluoride metabolite deposition from methoxyflurane [14,18]. Therefore, direct serum fluoride measurement is also important to investigate skeletal fluorosis risk. A threshold for serum fluoride levels associated with the onset of skeletal fluorosis is not immediately apparent in the literature [19-22]. Therefore, meta-analysis of the serum fluoride of the general public is also required to identify a healthy serum fluoride range not associated with skeletal fluorosis, against which individuals exposed to methoxyflurane might be compared.

This research hypothesized that emergency medical technicians (EMTs) would exhibit increasing serum fluoride concentrations after introduction of methoxyflurane. The absence of reported adverse effects due to occupational exposure was noted [23]. However, the accumulation of fluoride following repeated occupational exposure to methoxyflurane vapor has not been previously studied, and identifying whether such accumulation occurs is a necessary first step to quantifying risk and optimizing safety. Thus, this study directly measured serum fluoride over a prolonged period in order to determine renal toxic and skeletal fluorosis risk to ambulance officers who are administering methoxyflurane.

\section{MATERIAL AND METHODS}

The study was approved by the University of Canterbury Human Ethics Committee with ref. No. HEC 2017/23/LR, and by the ambulance service Research Committee. The study was registered with the Australian New Zealand Clinical Trials Registry with ID No. ACTRN12617001334392. 
Written informed consent was obtained from all participants prior to any blood measurement.

Meta-analysis of published serum fluoride levels associated with healthy individuals was performed by the following process. First, the healthy reference range for serum fluoride was determined by searching PubMed for literature reporting serum fluoride in healthy adults. The inclusion criteria were as follows: any study reporting serum fluoride levels for a group consisting of healthy persons with an absence of reported skeletal fluorosis or altered renal function, regardless of their occupational or environmental exposure to fluoride or any substance believed to alter fluoride levels. Only English language studies were considered. The analysis was performed using R 3.6.1. Subsequently, the meta-analysis of search results was conducted by the generic inverse variance method with a randomeffects model [24].

A New Zealand metropolitan ambulance service introduced methoxyflurane, administered via the Penthrox ${ }^{\circledR}$ inhaler with an activated carbon filter (Medical Developments International, Australia), as an analgesic option on June 1, 2017. Ambulance officers administered 3 or $6 \mathrm{ml}$ to patients, as needed for analgesia [25]. The Penthrox ${ }^{\circledR}$ inhaler contains a carbon filter which adsorbs vapor exhaled by the patient, limiting vapor from entering the workspace of the ambulance officer. However, uncertain patient compliance with exhaling through the filter implied that staff would be exposed to some methoxyflurane vapor during administration [6].

A prospective observational cohort study was undertaken. At first, EMTs were recruited by general requests for participation sent via the ambulance service's internal e-mail system, and respondents were provided further information and gave their written consent for participation, until the goal of 12 participants was achieved. This sample size was selected to provide $95 \%$ power to detect a $1 \mu \mathrm{mol} / \mathrm{l}$ difference between test results with $\mathrm{p}<0.01$, allowing for $30 \%$ attrition [26]. Consent was only given for the collection, analysis, and publication of serum fluoride results.

The inclusion criteria were as follows:

- EMTs' practice level;

- employment in full-time patient contact duties by the ambulance service;

- age $\geq 18$ years.

The reason why EMTs were recruited was that they can administer oral or inhaled analgesia agents, including methoxyflurane, but not intravenous agents [25]. Hence, it was assumed that EMTs would be more likely than other qualified staff to utilize methoxyflurane, and thus to be most exposed to methoxyflurane vapor. There were no exclusion criteria. The authors did not seek or obtain ethical approval to collect data on the participants' characteristics such as age, weight, or sex.

Blood serum measurements were taken in months $0,1,4,8$, 12,18 , and 24 following the introduction of methoxyflurane. The participants were e-mailed reminders at the start and mid-point of each of the 7 study months to provide a blood sample at a day and time convenient to them. Blood sampling was performed by a trained phlebotomist at a clinic convenient to each participant. Samples were separated locally and serum was sent to Canterbury Health Laboratories, Christchurch, New Zealand for analysis. Serum fluoride concentration was measured by a Thermo Scientific ${ }^{\mathrm{TM}}$ Orion $\mathrm{Star}^{\mathrm{TM}}$ A214 pH/ISE Benchtop Meter with a Thermo Scientific $^{\mathrm{TM}}$ fluoride ion specific electrode. Equipment was calibrated by the laboratory using suitable sodium fluoride standards in accordance with the manufacturer's instructions. Uncertainty of measurement was $\pm 0.48 \mu \mathrm{mol} / \mathrm{l}$ at $1 \mu \mathrm{mol} / \mathrm{l}$, and $\pm 2.11 \mu \mathrm{mol} / \mathrm{l}$ at $27 \mu \mathrm{mol} / \mathrm{l}$. The lower limit of quantification was $0.2 \mu \mathrm{mol} / \mathrm{l}$. Canterbury Health Laboratories is an entity accredited by International Accreditation New Zealand (IANZ) in all disciplines and for all medical testing procedures it performs, and is ISO 15189 accredited.

Exposure frequency data were not recorded due to an inability to directly observe the cohort, concern about 


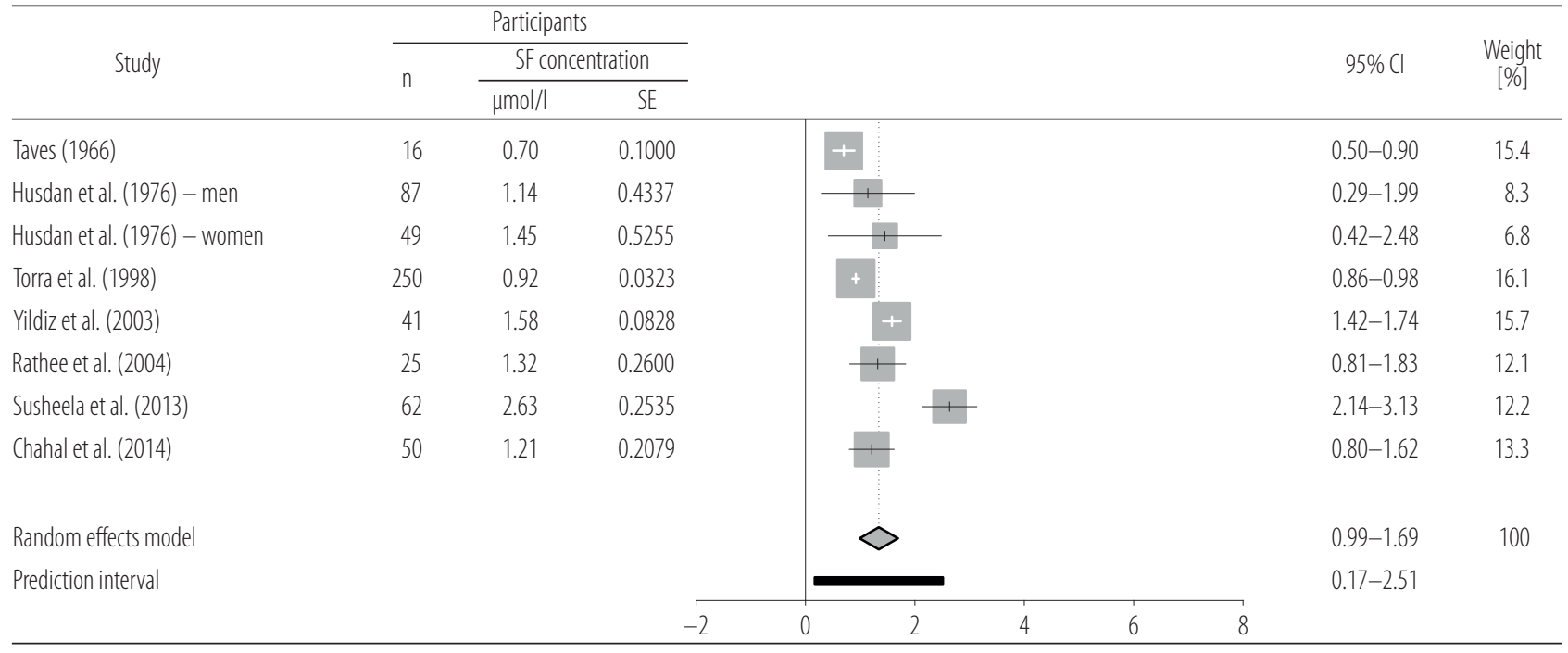

Heterogeneity: $I^{2}=94 \%, \tau^{2}=0.1975, p<0.001$.

The $95 \%$ CI was determined by the generic inverse variance method with a random-effects model, and is shown as the "prediction interval" (p < 0.001$)$.

Figure 1. Forest plot of serum fluoride (SF) ranges of healthy individuals

the reliability of the participants' self-reporting, and ethical and time constraints in setting up the study.

Two-sample, 2-sided Wilcoxon signed-rank tests were performed, comparing the serum fluoride results from each study month against the results from month 0 , removing from each test any participants who had not provided a blood sample in both the specific month and month 0 to ensure pairing. Two-sample 2-sided Kolmogorov-Smirnov tests were performed, comparing all serum fluoride results for each participant with a constant serum fluoride value equal to that participant's first test result. Statistical significance for all tests was defined as $\mathrm{p}<0.05$. The Kolmogorov-Smirnov test was selected after all serum fluoride test results had been received. Thus, results of that analysis should be regarded as hypothesis-generating.

The serum fluoride levels associated with skeletal fluorosis were determined by searching PubMed for literature reporting this association. Engauge v. 10.10 software was used to determine the value of serum fluoride and bone mineral density data points in figures.

\section{RESULTS}

\section{Identification of a healthy serum fluoride range}

Overall, 8 studies reporting serum fluoride ranges in healthy adults were identified [19-21,27-31]. Insufficient statistical measures were provided in 1 study, preventing its inclusion in the meta-analysis [21]. One other study reported ranges for men and women separately [28]. Therefore, these ranges were input as separate samples for meta-analysis. None of the studies included New Zealand subjects. Meta-analysis, as shown in Figure 1, determined mean $(95 \% \mathrm{CI})$ serum fluoride in healthy individuals to be $1.16 \mu \mathrm{mol} / 1$ (0.21-2.11) with $\mathrm{p}<0.001$, indicating statistically significant homogeneity supporting this determination of a normal range.

\section{Participants' serum fluoride results}

The target of recruiting 12 EMTs was achieved by June 15, 2017. One participant withdrew late during the study and ethical constraints prohibit presentation or discussion of that person's data. Some participants failed to undertake $\geq 1$ tests. 


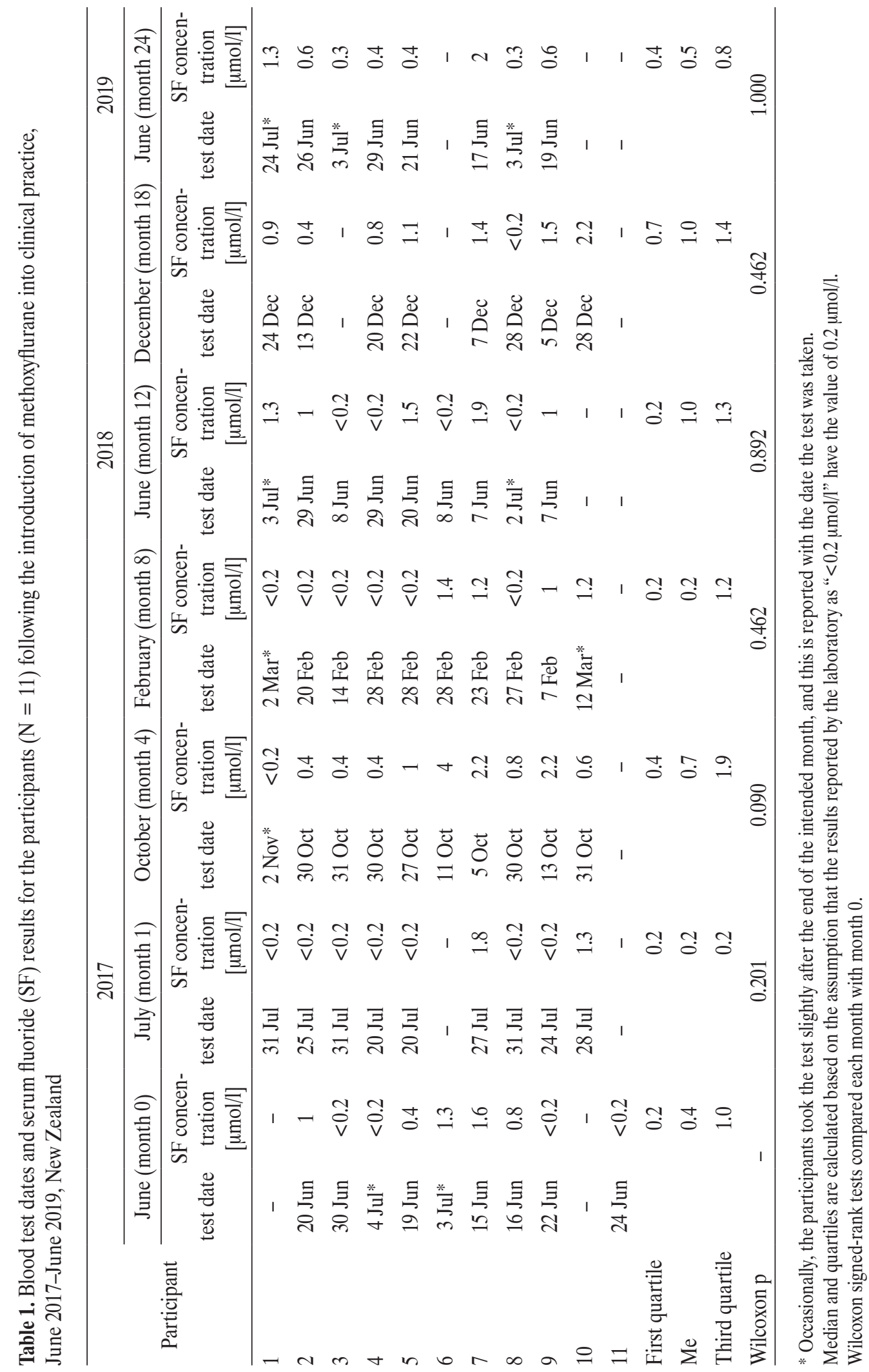


Table 2. Results of Kolmogorov-Smirnov tests for each participant's serum fluoride results against a constant serum fluoride value equal to that participant's initial test result, following the introduction of methoxyflurane into clinical practice, June 2017-June 2019, New Zealand

\begin{tabular}{|c|c|}
\hline Participant & Kolmogorov-Smirnov $p$ \\
\hline 1 & 0.395 \\
\hline 2 & 0.056 \\
\hline 3 & 0.865 \\
\hline 4 & 0.541 \\
\hline 5 & 0.541 \\
\hline 6 & 0.548 \\
\hline 7 & 0.203 \\
\hline 8 & 0.056 \\
\hline 9 & 0.056 \\
\hline 10 & 0.548 \\
\hline
\end{tabular}

One participant undertook only the initial blood test but did not withdraw formally from the study, and 6 participants provided blood samples for every requested study month.

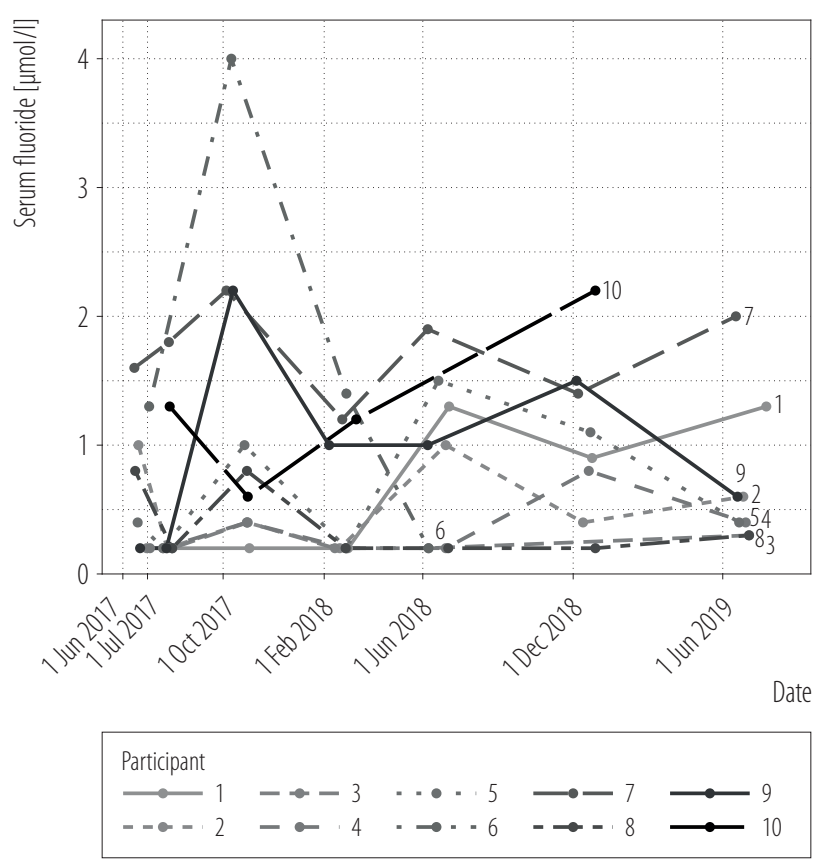

Figure 2. Serum fluoride results for participants 1-10, June 2017-June 2019, New Zealand

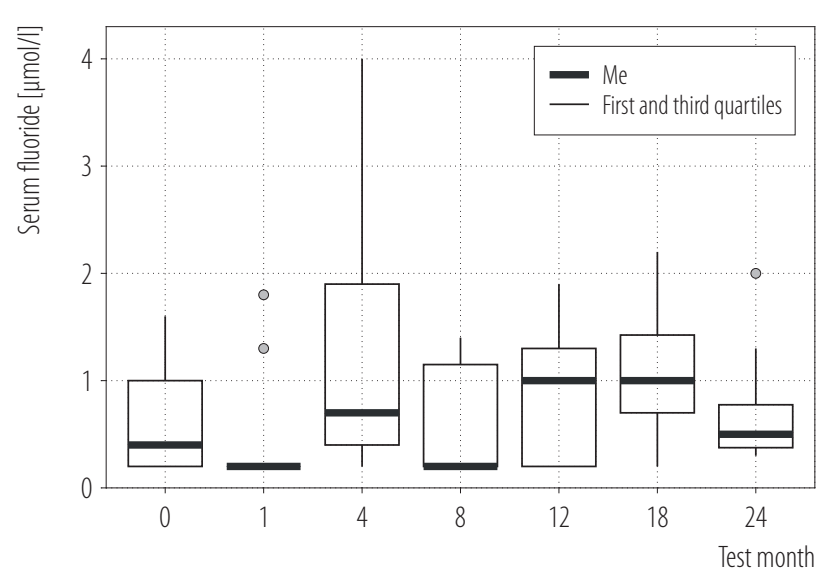

Vertical lines extend from the smallest observation greater than or equal to the first quartile minus 1.5 times the interquartile range, to the largest observation less than or equal to the third quartile plus 1.5 times the interquartile range; dots indicate outlier serum fluoride results not included within the vertical line range.

Figure 3. Box plots for serum fluoride in each test month, June 2017-June 2019, New Zealand

The resulting data set includes initial (baseline) values for 9 participants and longitudinal results for 10 participants, as shown in Table 1. Some results were below the lower limit of quantification. The analysis (Tables 1 and 2, Figures 2 and 3) and discussion of the results assume those results to be equal to the lower limit of quantification: $0.2 \mu \mathrm{mol} / \mathrm{l}$. To determine whether this assumption introduced error, an analysis was also performed with these values equal to 0.0 , which did not elicit any new statistical significance in any results.

Longitudinal results for the participants are displayed in Figure 2, and summary statistics for each month are shown in Table 1 and Figure 3. The overall median (first quartile, third quartile) of serum fluoride was $0.4 \mu \mathrm{mol} / \mathrm{l}$ (first and third quartiles: $0.2,1.3$ ) with $\max 4.0 \mu \mathrm{mol} / \mathrm{l}$. The p-values determined by Wilcoxon signed-rank tests for the difference between month 0 and each subsequent month are shown in Table 1, and support a conclusion that there is no statistically significant change in serum fluoride over time. The results of Kolmogorov-Smirnov tests for 10 participants are shown in Table 2. This compares each partici- 
pant's serum fluoride results against a constant serum fluoride value equal to that participant's initial test result, to identify whether a statistically significant change occurred. No results met the criteria for statistical significance, though several were close.

\section{Identification of skeletal fluorosis thresholds}

Overall, 6 studies reporting serum fluoride levels associated with skeletal fluorosis were identified [21,22,29, 30,32,33]. The lowest reported serum fluoride level for a person with some evidence of skeletal fluorosis was $3.42 \mu \mathrm{mol} / 1$ [29]. However, the lowest serum fluoride level for a person satisfying skeletal fluorosis criteria with spinal bone mineral density measured by dual-energy X-ray absorptiometry greater than 2 standard deviations above the control mean was $3.65 \mu \mathrm{mol} / 1$ [29]. This latter value was selected as the lowest observed adverse effect level (LOAEL). The lowest serum fluoride at which standard radiologic features of skeletal fluorosis were evident was $16.63 \mu \mathrm{mol} / 1$ [21].

\section{DISCUSSION}

This study observed a small statistically insignificant increase in serum fluoride in EMTs after methoxyflurane had been introduced into clinical practice (Tables 1 and 2, Figures 2 and 3). A power analysis was conducted to identify the appropriate sample size to detect large differences $(1 \mu \mathrm{mol} / \mathrm{l})$ in serum fluoride, accounting for attrition. The study recruited the number of participants identified by that power analysis, implying that the study was appropriately powered to test a hypothesis of large increases in serum fluoride concentrations after introduction of methoxyflurane. However, the large number of missing test results limits the determination of statistical significance.

\section{Comparison with a healthy serum fluoride range}

The meta-analysis determined a 95\% CI for healthy serum fluoride to be $0.21-2.11 \mu \mathrm{mol} / \mathrm{l}$ (Figure 1). This meta-anal- ysis is important as it provides a comparison and evaluation of the study of serum fluoride in ambulance staff exposed to a substance known to alter serum fluoride.

Serum fluoride concentration in month 0 established a participant's baseline serum fluoride of $0.2-1.6 \mu \mathrm{mol} / 1$ (Table 1). Participants 1 and 10 did not provide their blood sample in month 0 , but their serum fluoride values in month 1 were $<0.2$ and $1.3 \mu \mathrm{mol} / 1$, respectively. This outcome suggests that all participants were within the identified healthy range when methoxyflurane was introduced into clinical practice.

The results in Table 1 show a mild variation of serum fluoride for the participants over the 24-month study period. One test result exceeded the $95 \% \mathrm{CI}$ for healthy serum fluoride (participant 6 in month $4, S_{\mathrm{f}}=4.0 \mu \mathrm{mol} / \mathrm{l}$ ), while 3 other test results were at the upper limit of the $95 \%$ CI (participants 7 and 9 in month 4; and participant 10 in month $18, \mathrm{~S}_{\mathrm{f}}=2.2 \mu \mathrm{mol} / \mathrm{l}$ on each occasion). This set of higher results suggests the possibility of an effect from occupational exposure to methoxyflurane, and the possibility of methoxyflurane inconsistently causing an elevation of serum fluoride above a normal healthy adult range.

\section{Comparison with the renal toxic threshold}

Serum fluoride remained well below the previously suggested single-dose renal toxic threshold of $40 \mu \mathrm{mol} / \mathrm{l}[5,6]$. The peak serum fluoride value determined by this research (Table 1) is only $10 \%$ of that threshold. There is no data available of whether this toxic threshold would change with frequent exposure and chronic serum fluoride elevation. However, this difference and the results presented imply safety from renal toxicity for these ambulance officers occupationally exposed to methoxyflurane.

\section{Skeletal fluorosis risk}

Skeletal fluorosis is associated with a wide range of serum fluoride levels [21,22,29,30,32,33], from 45 patients 


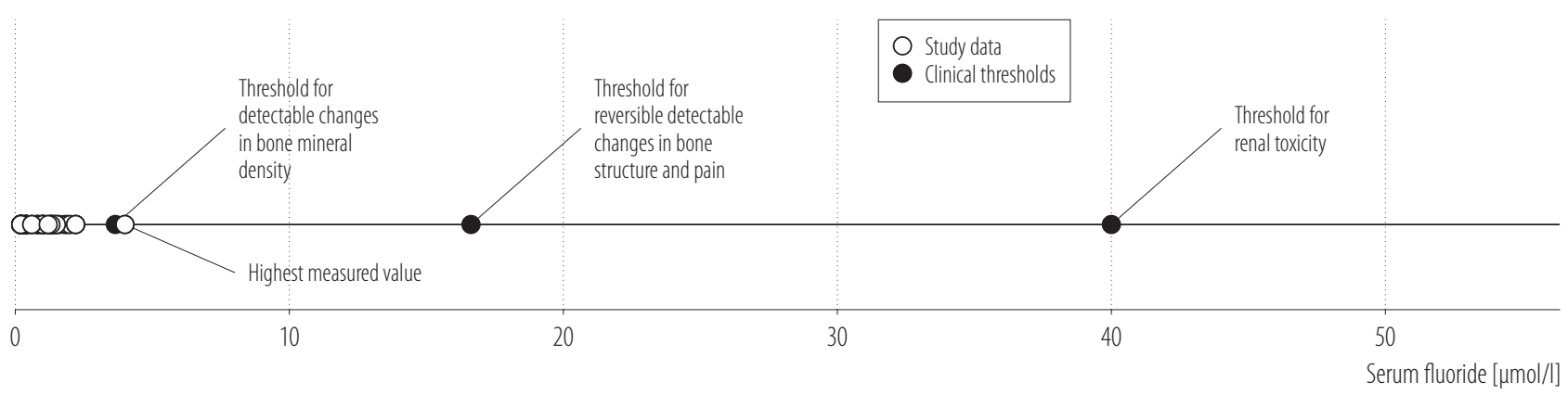

Figure 4. Summary of all participants' serum fluoride results compared with clinical thresholds, June 2017-June 2019, New Zealand

with mean serum fluoride of $5.79 \mu \mathrm{mol} / \mathrm{l}$ associated with a measurable change in bone mineral density [29] to a case report with serum fluoride of $205.28 \mu \mathrm{mol} / \mathrm{l}$ associated with pronounced painful skeletal changes [22]. This very wide range of serum fluoride values, with the highest value identified in this study corresponding to approx. 2-69\% of those mean values, coupled with an absence of case studies of skeletal fluorosis in ambulance officers at other sites administering methoxyflurane repeatedly, implies a reasonable but unsatisfying degree of safety.

The LOAEL for skeletal fluorosis is $3.65 \mu \mathrm{mol} / \mathrm{l}$ of serum fluoride, likely due to long-term ingestion of contaminated ground water [29]. One result exceeded this LOAEL (participant 6 in month $4, \mathrm{~S}_{\mathrm{f}}=4.0 \mu \mathrm{mol} / \mathrm{l}$ ), suggesting a possibility of skeletal fluorosis effects for some ambulance officers ( 1 in 10 EMTs in this case). This subject was informed by the study author of that result compared with the identified thresholds, and encouraged to contact a general practitioner. That participant's serum fluoride level did not remain above the LOAEL in subsequent tests, and the period of elevated serum fluoride required for the adverse effect to occur is unknown. Notably, the highest serum fluoride result was $24 \%$ of the lowest level known to be associated with radiologic evidence of fluorosis [21]. Figure 4 illustrates serum fluoride results for all participants compared with identified clinical thresholds for skeletal fluorosis and renal toxicity.

\section{Serum fluoride accumulation}

The Wilcoxon signed-rank test evaluates a hypothesis of similarity between repeated groups of measurements of the same subjects. These tests did not identify any statistically significant differences in blood test results compared with results from month 0 . The Kolmogorov-Smirnov test evaluated a hypothesis of similarity for each participant's test results over the study period from their baseline. These tests also did not identify statistically significant changes in serum fluoride for any participant (Tables 1 and 2). Therefore, this study provided no statistically significant evidence that occupational exposure to methoxyflurane led to increasing serum fluoride. More frequent serum fluoride sampling may have improved the likelihood of achieving statistical significance.

\section{Limitations}

This research has a number of limitations. To protect participants' anonymity, ethical approval was not sought for the collection of demographic data such as participants' age, sex, or fluoride intake from fluoridated water or other sources, as the group of ambulance officers being approached is relatively small and such information would potentially identify them to the study authors. Therefore, the effect of these variables cannot be determined. Methoxyflurane was introduced into practice on the June 1, 2017. Due to ethical and organizational constraints, month 0 blood tests were taken on June 15-July 4, 2017. 
Therefore, the participants may have been exposed to methoxyflurane prior to the baseline blood test, and that result might not represent a non-exposed value, thus limiting the potential to detect any increase from a non-exposed baseline. This study, nonetheless, determined that the levels of serum fluoride in a cohort of EMTs were generally within normal limits.

Furthermore, the study was not blinded and the participants were able to opt-in to receiving each test result. Therefore, the participants may have adjusted their methoxyflurane administration behavior in response to their test results. This potential self-regulation of administration amongst the participants may have led to lower than representative rates of administration and, thus, exposure. However, any change in behavior cannot be confirmed within the constraints of the ethical approval obtained, and this study makes no attempt to correlate frequency or duration of exposure of individual participants with serum fluoride results.

\section{Clinical implications}

Previous studies have attempted to determine occupational risk by extrapolation from limited patient anesthesia data $[6,7,11]$. This research is the first report of serum fluoride associated with occupational exposure in the modern setting using the Penthrox ${ }^{\circledR}$ inhaler. Direct measurements of serum fluoride provide a much greater certainty than extrapolation over several orders of magnitude. While extrapolation did not identify values approaching a singledose renal toxic threshold, or within a skeletal fluorosis range, the direct measurement undertaken in this research provides more convincing evidence of safety. Additionally, this study provides evidence of renal safety and evidence suggesting that fluoride accumulation does not occur in EMTs with repeated methoxyflurane exposures, which extrapolation from single high-dose data cannot provide. Furthermore, skeletal fluorosis is identified as a risk associated with EMTs' occupational exposure to methoxyflu- rane. Further quantification of skeletal fluorosis risk may be a valuable subject for future research.

The present study involved the presence of an activated carbon filter on the patient's exhalation. Filtration is a potentially important factor that should be considered in the interpretation and design of studies. Given other evidence for risks associated with occupational exposure to methoxyflurane, it is suggested that conservative clinical practice would be to use activated carbon filters until such time as the effect of filtration can be better understood. Investigation of the degree of occupational exposure experienced under various conditions would assist in the determination of risks faced by ambulance officers and healthcare workers in other settings. Serum fluoride measurement with greater fidelity (more frequently than approximately every 1-6 months as was the case in this study), and/or a larger number of subjects than included in this study, might improve the degree of certainty of the risk posed by occupational methoxyflurane exposure. Determination of serum fluoride from methoxyflurane exposure in environments other than ambulance care, such as in a hospital or clinical setting, would be of value to the wider healthcare community. Until the degree of the risk posed by methoxyflurane is further clarified, it may be beneficial for ambulance officers and other healthcare staff to maximize environmental ventilation in order to minimize their occupational exposure and consequent skeletal fluorosis risk.

\section{CONCLUSIONS}

There was no statistically significant change in the serum fluoride results across the combined data set. Thus, there was no evidence of EMTs' exposure to methoxyflurane resulting in sustained increased serum fluoride levels. There was no evidence to support the hypothesis that increasing serum fluoride occurs over a prolonged (up to 2-year) period. One serum fluoride result exceeded, and some serum fluoride results reached, the upper limit of the expected reference range. The maximum serum fluoride level was only $10 \%$ of the pro- 
posed acute renal toxic threshold, suggesting ambulance officer safety from acute renal toxicity within the administration parameters of the study subjects. The margin for safety from skeletal fluorosis effects is less clear, and the study could not exclude the possibility of some risk of mild skeletal fluorosis in the form of increased bone mineral density.

\section{ACKNOWLEDGMENTS}

The authors wish to acknowledge the staff of Canterbury Health Laboratories, who performed the serum fluoride measurement and who kindly provided their insight with the technical process and result interpretation.

\section{REFERENCES}

1. Blair HA, Frampton JE. Methoxyflurane: a review in trauma pain. Clin Drug Investig. 2016;36(12):1067-73, https://doi. org/10.1007/s40261-016-0473-0.

2. Medical Developments International [Internet]. Scoresby: The Organization; 2016 [cited 2020 Aug 19]. Material safety data sheet. Available from: http://www.medicaldev.com/wpcontent/uploads/2017/03/MSDS-Penthrox-April-2016.pdf.

3. Allison SJ, Docherty PD, Pons D, Chase JG. Exposure to methoxyflurane: Low-dose analgesia and occupational exposure. Aus J Paramed. 2020;17:1-13, https://doi.org/10.33151/ajp.17.712.

4. Yoshimura N, Holaday DA, Fiserova-Bergerova V. Metabolism of methoxyflurane in Man. Anesthesiology. 1976;44(5):372-9.

5. Cousins MJ, Mazze RI, Barr GA, Kosek JC. Methoxyflurane nephrotoxicity: a study of dose response in man. JAMA. 1973;225(13):1611-6, https://doi.org/10.1001/jama.225.13.1611.

6. Frangos J, Mikkonnen A, Down C. Derivation of an occupational exposure limit for an inhalation analgesic methoxyflurane (Penthrox). Regul Toxicol Pharmacol. 2016;80:210-25, https://doi.org/10.1016/j.yrtph.2016.05.012.

7. Allison SJ, Docherty PD, Pons D, Chase JG. A bootstrap approach for predicting methoxyflurane occupational exposure in paramedicine. In: 20th World Congress of The International Federation of Automatic Control; 2017 Jul 13; Toulouse, France. IFAC-PapersOnLine: Elsevier; 2017. p. 6666-71.
8. Cousins MJ, Nishimura TG, Mazze RI. Renal effects of lowdose methoxyflurane with cardiopulmonary bypass. Anesthesiology. 1972;36(3):286-92, https://doi.org/10.1097/00000 542-197203000-00017.

9. Crandell WB, Pappas SG, MacDonald A. Nephrotoxicity associated with methoxyflurane anesthesia. Anesthesiology. 1966;27(5):591-607, https://doi.org/10.1097/00000542-19660 9000-00010.

10. Mazze RI, Shue GL, Jackson SH. Renal dysfunction associated with methoxyflurane anesthesia: a randomised, prospective clinical evaluation. JAMA. 1971;216(2):278-88, https://doi.org/10.1001/jama.1971.03180280032006.

11. Allison SJ, Docherty PD, Pons D, Chase JG. A bootstrap approach for predicting fluoride toxicity in paramedics after occupational methoxyflurane exposure. IFAC J Systems Control. 2019;9(30), https://doi.org/10.1016/j.ifacsc.2019.100061.

12. Institut für Arbeitsschutz der Deutschen Gesetzlichen Unfallversicherung [Internet]. 2020 [cited 2020 Dec 3]. GESTIS International Limit Values - Methoxyfluran. Available from: https://limitvalue.ifa.dguv.de/.

13. Ruff R, Kerr S, Kerr D, Zalcberg D, Stevens J. Occupational exposure to methoxyflurane administered for procedural sedation: an observational study of 40 exposures. $\mathrm{Br}$ J Anaesth. 2018;120(6):1435-7, https://doi.org/10.1016/j.bja. 2018.01.029.

14. Fiserova-Bergerova V. Fluoride in bone of rats anesthetised during gestation with enflurane or methoxyflurane. Anesthesiology. 1976;45(5):483-6.

15. Fiserova-Bergerova $\mathrm{V}$. Changes of fluoride content in bone: an index of drug defluorination in vivo. Anesthesiology. 1973; 28:345-51, https://doi.org/10.1097/00000542-197304000-00007.

16. World Health Organization [Internet]. Geneva: The Organization; 2019 [cited 2020 Aug 19]. Inadequate or excess fluoride: a major public health concern. Available from: https:// apps.who.int/iris/bitstream/handle/10665/329484/WHOCED-PHE-EPE-19.4.5-eng.pdf.

17. World Health Organization [Internet]. Malta: Gutenberg; 2011 [cited 2020 Aug 19]. Guidelines for drinking-water 
quality. Available from: https://apps.who.int/iris/bitstream/ handle/10665/44584/9789241548151_eng.pdf.

18. Desmond JW. Methoxyflurane nephrotoxicity. Canad Anaesth Soc J. 1974;21(3):294-307, https://doi.org/10.1007/bf0 3005734.

19. Torra M, Rodamilans M, Corbella J. Serum and urine ionic fluoride: normal range in a nonexposed population. Biol Trace Elem Res. 1998;63(1):67-71, https://doi.org/10.1007/ BF02785278.

20. Rathee N, Garg P, Pundir CS. Correlative study of fluoride content in urine, serum and urinary calculi. Indian J Clin Biochem. 2004;19(2):100-2, https://doi.org/10.1007/BF02894265.

21. Gerber B, Guggenberger R, Fasler D, Nair G, Manz MG, Stussi G, et al. Reversible skeletal disease and high fluoride serum levels in hematologic patients receiving voriconazole. Blood. 2012;120(12):2390-4, https://doi.org/10.1182/ blood-2012-01-403030.

22. Rackoff P. Skeletal fluorosis - a tricky diagnosis. Arthritis Rheumatol. 2015;67(10):2701, https://doi.org/10.1002/art.39237.

23. Therapeutic Goods Administration. Medicines Safety Update. Methoxyflurane and occupational exposure. Australian Prescriber [Internet]. 2014 [cited 2020 Aug 19];37(2):63. Available from: https://www.tga.gov.au/sites/default/files/msu2014-04.pdf.

24. Borenstein M, Hedges LV, Higgins JP, Rothstein HR. A basic introduction to fixed-effect and random-effects models for meta-analysis. Res Synth Methods. 2010;1(2):97-111, https://doi.org/10.1002/jrsm.12.
25. Wellington Free Ambulance. Clinical procedures and guidelines - comprehensive edition. Wellington Free Ambulance; 2016.

26. Whitley E, Ball J. Statistics review 4: sample size calculations. Crit Care. 2002;6(4):335-41, https://doi.org/10.1186/cc1521.

27. Taves DR. Normal human serum fluoride concentrations. Nature. 1966;211(5045):192-3, https://doi.org/10.1038/211192b0.

28. Husdan H, Vogl R, Oreopoulos D, Gryfe C, Rapoport A. Serum ionic fluoride: normal range and relationship to age and sex. Clin Chem. 1976;22(11):1884-8.

29. Yildiz M, Akdogan M, Tamer N, Oral B. Bone mineral density of the spine and femur in early postmenopausal Turkish women with endemic skeletal fluorosis. Calcif Tissue Int. 2003;72(6):689-93, https://doi.org/10.1007/s00223-002-2097-z.

30. Susheela AK, Mondal NK, Singh A. Exposure to fluoride in smelter workers in a primary aluminum industry in India. Int J Occup Environ Med. 2013;4(2):61-72.

31. Chahal A, Bala M, Dahiya RS, Ghalaut VS. Comparative evaluation of serum fluoride levels in patients with and without chronic abdominal pain. Clin Chim Acta. 2014;429: 140-2, https://doi.org/10.1016/j.cca.2013.11.031.

32. Zhu C, Zhou S, Liu L, Song Y. Multiple levels of spinal canal stenosis in endemic skeletal fluorosis. Joint Bone Spine. 2017;84(6):737, https://doi.org/10.1016/j.jbspin.2017.01.009.

33. Hewavithana PB, Jayawardhane WM, Gamage R, Goonaratna C. Skeletal fluorosis in Vavuniya District: an observational study. Ceylon Med J. 2018;63(3):139-42, https://doi. org/10.4038/cmj.v63i3.8723.

This work is available in Open Access model and licensed under a Creative Commons Attribution-NonCommercial 3.0 Poland License - http://creativecommons.org/ licenses/by-nc/3.0/pl/deed.en. 